East African Medical Journal Vol. 85 No. 3 March 2008

CAUSES AND PATTERN OF UNILATERAL HAND INJURIES

W. O. Kaisha, MBChB, MMed (Surg), Assistant Lecturer, Department of Human Anatomy and S. Khainga, MBChB, MMed (Surg), Lecturer, Department of Surgery, College of Health Sciences, University of Nairobi, P. O. Box 19676 - 00202, Nairobi, Kenya

Request for reprints to: Dr. W. O. Kaisha, P. O. Box 368-00202, Nairobi, Kenya

\title{
CAUSES AND PATTERN OF UNILATERAL HAND INJURIES
}

\author{
W. O. KAISHA and S. KHAINGA
}

\begin{abstract}
Objective: To assess the causes and pattern of hand injuries in patients with isolated unilateral acute hand injuries managed at the Kenyatta National Hospital (KNH). Design: A prospective cross-sectional descriptive study. Setting: Kenyatta National Hospital, Nairobi, Kenya, between May and August 2006. Subjects: All patients with isolated unilateral acute hand injuries who presented at the casualty department.

Results: A total of 99 patients were recruited. The mean age was 28.2 years with the modal age being 21-30 years. More males were injured than females. Occupational injuries and assaults were the most prevalent causes of hand injury. Majority of the injuries included lacerations, fractures and tendon injuries. The distal phalanges of the ring and long fingers were the most common sites of injury on the digits.

Conclusion: Occupational hand injuries, a largely preventable problem, are the most prevalent cause of hand injury. This offers opportunity for strategies in preventing a large number of hand injuries by initiating safety measures at the work place.
\end{abstract}

\section{INTRODUCTION}

The hand is a super tool, an organ of communication, used for gestures and expression of a range of emotions; determination, control and environment manipulation (1). Given thisimportance, hand injuries are a real burden to society and therefore worthwhile to be prevented (2). There is a need to record data on the background of the injuries and their consequences. Documentation would quantify society burden and assist in managing long-term effects of the injuries. Understanding the causes would contribute to prevention strategies. This study documents the demographic characteristics, causes, site and patterns of hand injuries at an urban referral hospital in Kenya.

\section{MATERIALS AND METHODS}

Study area: Kenyatta National Hospital (KNH), a national referral and teaching hospital, which also receives most of the emergency cases in the greater Nairobi region.

Subjects: All consecutive patients with isolated unilateral acute hand injuries who presented at the casualty department during the period between May and August 2006 and satisfied the inclusion criteria below.

Data collection. Patients recruited were evaluated and information on age, gender, education level, cause of injury, site and structures injured obtained. Sites were categorised as individual digits versus the carpus (rest of the hand minus the digits). Radiographs were obtained when indicated and those who required operative management were followed-up to document additional injuries.

Eligibility:Subjects must have had a laceration, crush, avulsion, puncture, fracture, contusion or dislocation involving any part of the hand. Hand being considered to be any part distal to the distal wrist crease. Those with burn injuries, previous hand injury and bilateral injuries were excluded.

Ethical consideration: Approval was sought from the University of Nairobi and the Kenyatta National Hospital Research and Ethics Committee. Written informed consent was obtained from the participants. Data analysis: SPSS 11.5 software was used for data entry and analysis. Student's $t$-test was used to compare the means. 


\section{RESULTS}

Patient characteristics: A total of 99 patients were recruited. The age range was 2 to 59 years with a modal age set of 21-30 years followed closely by 3140 year group. The extremes of ages formed the least group of patients (Table 1 ). The sample population had a mean age of 28.2 years, a median age of 26 years with a standard deviation of 9.5. The mean ages for males (27 years) and females (30 years) were statistically similar $(\mathrm{p}=0.33)$.

There were $78(78.9 \%)$ male and $21(21.2 \%)$ female patients giving a male to female ratio of 3.7: 1 . Most patients had primary level of education 52 $(52.5 \%)$ followed by those with secondary level education $34(34.3 \%),(\mathrm{n}=9)$ nine $(9.2 \%)$ had tertiary education while four (4\%) had no formal education (Table 1).

Table 1

Social demographic characteristic of the study population

\begin{tabular}{lrr}
\hline Characteristic & Frequency & $(\%)$ \\
\hline Age distribution $(\mathrm{n}=99)$ & 2 & 2.0 \\
$0-10$ & 14 & 14.1 \\
$11-20$ & 45 & 45.5 \\
$21-30$ & 27 & 27.3 \\
$31-40$ & 9 & 9.1 \\
$41-50$ & 2 & 2.0 \\
$51-60$ & & \\
Sex $(\mathrm{n}=99)$ & 78 & 78.8 \\
Male & 21 & 21.2 \\
Female & & \\
Level of education $(\mathrm{n}=99)$ & 4 & 4.0 \\
None & 52 & 52.5 \\
Primary & 34 & 9.3 \\
Secondary & 9 & 9.2 \\
College & & \\
\hline
\end{tabular}

Figure 1

Causes of the injuries

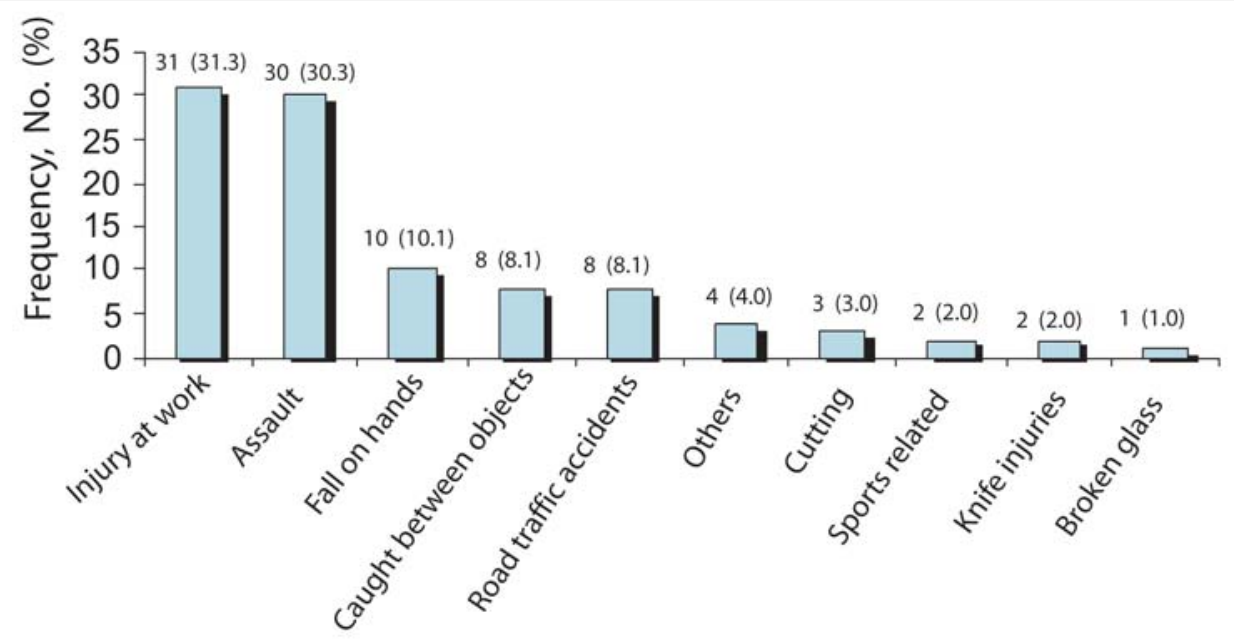


Cause of injury: The most common cause of injury (31.3\% Injury characteristics $n=31$ ), was work or machine related (occupational). Other causes included assaults $(30.3 \%, \mathrm{n}=30)$, falls $(10.1 \%)$, hand being caught in objects $(8.1 \%)$ and road traffic accidents $(8.1 \%)$. Other causes accounted for $10 \%$ of the cases (Figure 1).

Site of injury: The digits were the most prevalent site of injury $(75.8 \%)$. The most affected digits were the ring $(19.6 \%)$ and the index fingers $(17.5 \%)$. The distal phalanges of long and ring fingers were each injured at a frequency of $9.8 \%$ while that of index finger was $9.1 \%$. The proximal phalanx of thumb was affected $7.6 \%$ of the time (Table 2).

Pattern of injury: A variety of injuries were noted. These affected the skin, bones, nerves, joints and tendons. The skin was injured in $74.75 \%$ of the cases of which $42.4 \%$ were lacerations and $32.3 \%$ contusions. In $25.3 \%$ of the cases the skin was intact (Figure 2).

Distribution of fractures: There were 76 fractures with $55(72.4 \%)$ involving the phalanges, while 19 (25.0\%) involved metacarpals. Fractures occurred on carpal bones in two (2.6\%) cases (Table 3). The distal phalanx of the long finger was the most fractured bone $11(20 \%)$, followed by the distal phalanx of ring finger eight $(14.5 \%$ ) (Table 3$)$. Among the metacarpals, the second metacarpal was the most fractured seven (33.3\%), followed by the fifth metacarpal four $(19 \%)$, with the third being least injured two $(9.5 \%)$. The scaphoid and hamate were the only carpal bones fractured (Table 3 ).

Table 2

Site of injury

\begin{tabular}{|c|c|c|c|}
\hline \multicolumn{4}{|c|}{ Position (Phalanges) } \\
\hline & Proximal & Middle & Distal \\
\hline & No. $(\%)$ & No. $(\%)$ & No. $(\%)$ \\
\hline Thumb & $\begin{array}{ll}10 & 7.6\end{array}$ & $--^{*}$ & 4.5 \\
\hline Index finger & 6.1 & 2.3 & 129.1 \\
\hline Long finger & 2.3 & 4.5 & $13 \quad 9.8$ \\
\hline Ring finger & 5.3 & 4.5 & $13 \quad 9.8$ \\
\hline Little finger & 6.1 & 1.5 & 2.3 \\
\hline Carpus & $324.2^{*}$ & & \\
\hline
\end{tabular}

* No middle for thumb

* No divisions for carpus

Figure 2

Skin injury

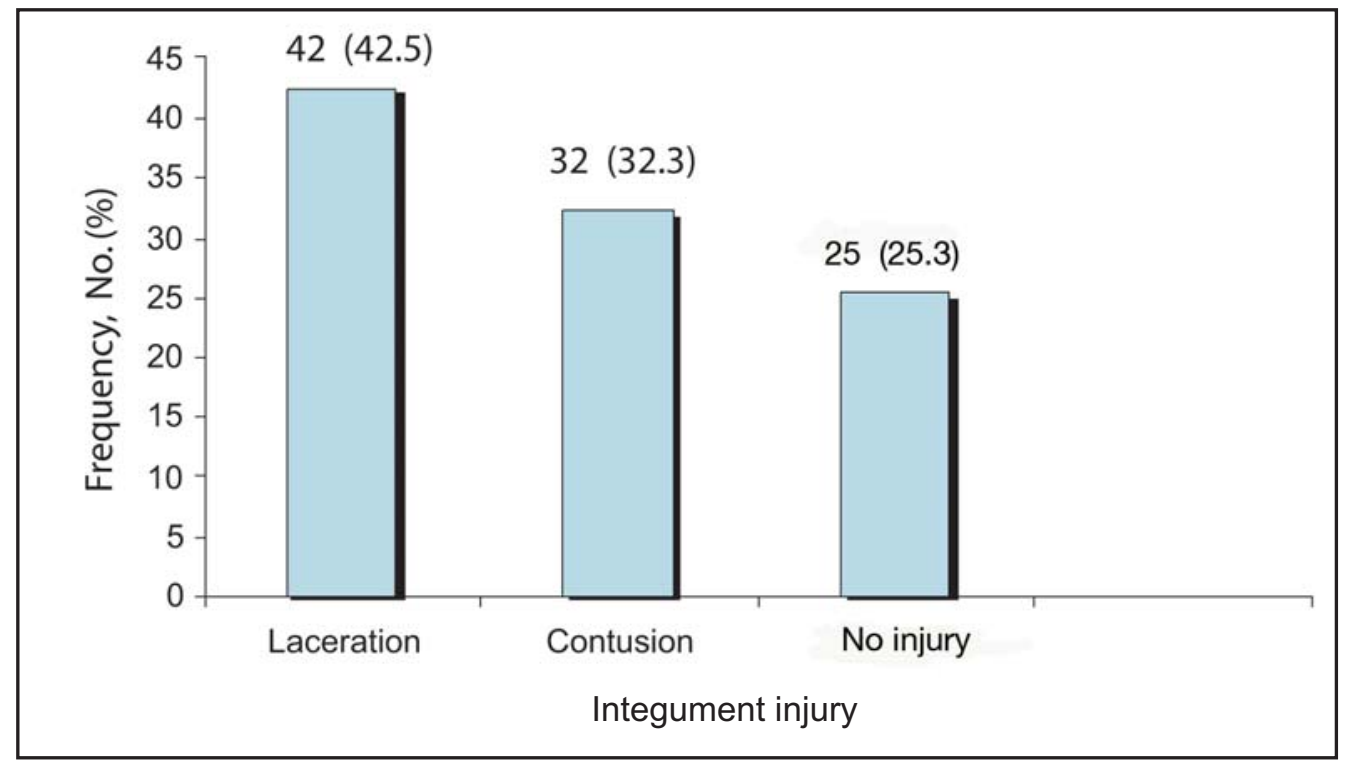




\section{Table 3}

\section{Distribution of fractures}

\begin{tabular}{lr}
\hline Phalanges & $55(72.4 \%)$ \\
Metacarpal & $19(25.0 \%)$ \\
Carpals & $2(2.6 \%)$
\end{tabular}

Phalangeal fractures

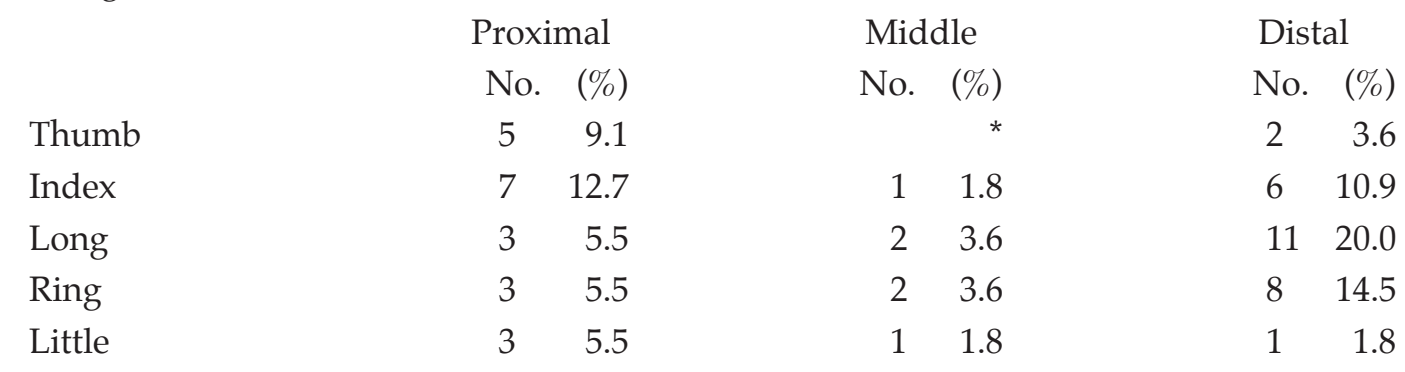

* No middle for thumb

Carpal and metacarpal fractures

Finding

Metacarpal

No. $(\%)$

$1^{\text {st }}$

$3 \quad 14.3$

$2^{\text {nd }}$

$\begin{array}{ll}7 & 33.3\end{array}$

$3^{\text {rd }}$

29.5

$4^{\text {th }}$

$3 \quad 14.3$

$5^{\text {th }}$

$\begin{array}{ll}4 & 19.0\end{array}$

\section{Carpal}

$\begin{array}{lll}\text { Scaphoid bone } & 1 & 4.8\end{array}$

Hamate bone

$1 \quad 4.8$

Nerve injuries: The prevalence of nerve injuries was $2 \%$ which involved the median and ulnar nerves.

a joint dislocation with the interphalangeal joint being Joint injury (dislocation). Nine patients $(10 \%)$ had the most affected five $(55.6 \%)$. The metacarpophalangeal joint was involved in two (22.2) (Figure3).

\section{Figure 3}

Joint dislocation

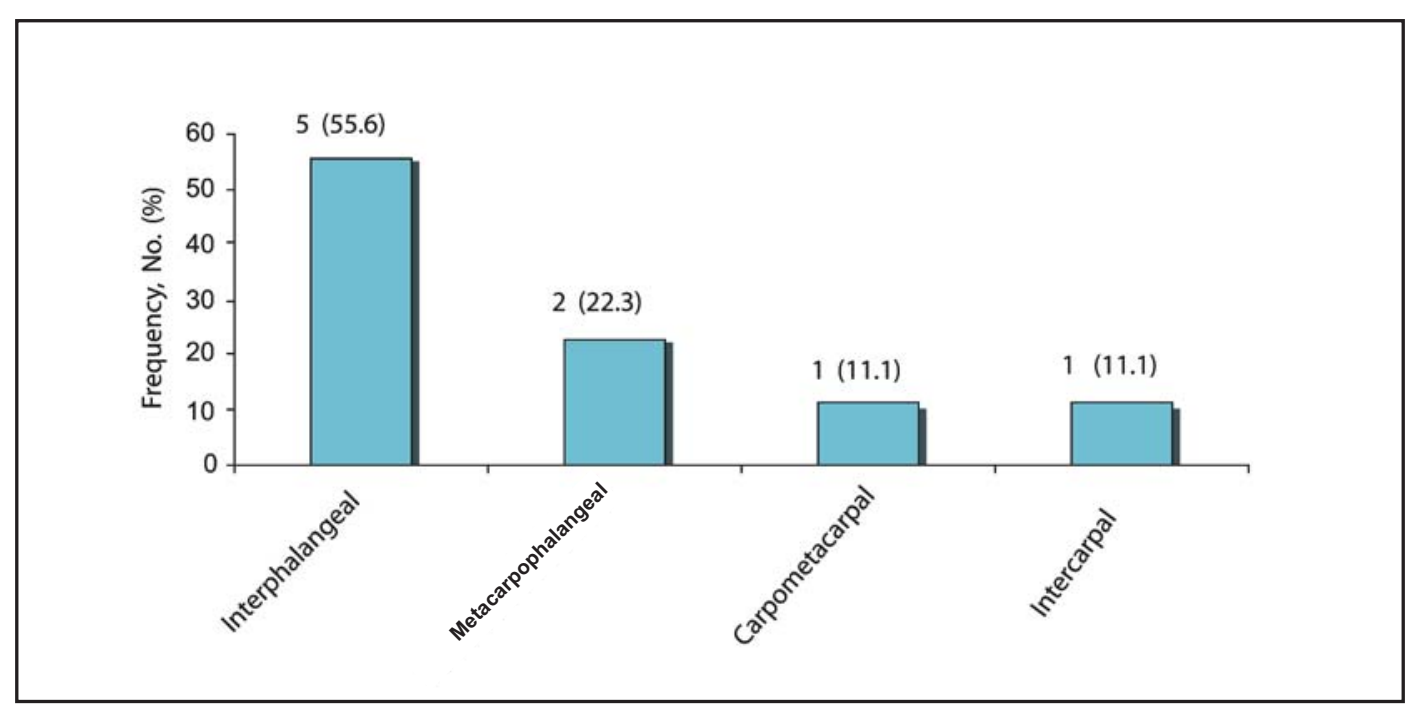


Injured tendons. Seventeen patients had tendon injuries, with 21 individual tendon injuries being identified. The flexor tendons were affected more than the extensors. The most prevalent tendon injuries were flexor digitorum superficialis followed by flexor digitorum profundus and extensor digitorum communis (Table 4).

\section{Table 4}

\section{Distribution of injured tendons}

\begin{tabular}{lc}
\hline & No. \\
\hline Flexor digitorum superficialis & 5 \\
Flexor digitorum profundus & 4 \\
Extensor communis & 4 \\
Flexor pollicis longus & 3 \\
Extensor indicis & 3 \\
Others & 2 \\
\hline
\end{tabular}

\section{DISCUSSION}

Age: Nearly all the age sets were affected by hand injury. However the modal age set was the 21-30 year group who consisted $45.5 \%$ of the patients. These findings compare well with other studies (3-6). According to Wanjohi, a similar modal group formed $39.9 \%$ of patients with hand fractures (3). These results are also consistent with others in Northern Ireland and Qatar $(4,5)$. However, Larsen et al in a study in The Netherlands and Denmark described the peak of injury to be in teenagers (6). These were largely due to recreational causes. This difference could be attributed to presence of less work placerelated injuries which usually occur among older individuals. However the distribution across age groups differs with Shaheen et al reporting a higher figule of $12 \%$ in thel-10 year group while Hill et al had about $10 \%(4,5)$. In the current study only $2 \%$ belonged to the 1-10 year group. This may be explained by differences in the definition and case selection of patients. Hill's study had loose selection criteria for hand injury in which the wrist was included (4).

Sex: Males formed a disproportionately high group of patients in this study, with a male to female ratio of 3.7:1. The figure compares well with Eastern European country of Poland (7) where male-female ratio was 4:1, but is higher than that in Northern Ireland (2.2:1) and Denmark (1.6:1) (4,8). A possible explanation may be that women are more involved in the economies of western European countries. However the ratio is quite low compared to Qatar's figures 10.1: 1, which may be due to cultural issues that hinder women's participation in society (5).
Education level: Most of the patients had primary level education and these tended to be the ones with occupational injuries and assaults. This group tends to be manual workers with little safety education. In Shaheen's study $59 \%$ of the subjects injured were manual workers, which he attributed to laxity of implementation of work place safety measures (5).

Causes of injury: The aetiology of injuries was varied with work-related $(31 \%)$ causes and assault $(30 \%)$ being the two leading causes, while falls and hand being caught in objects were next in line. This pattern may reflect the socio-economic state of the victims and the country's level of development. Compared to industrialised country like Qatar (5), this differs greatly as industrial causes accounted for $59 \%$ with domestic and recreational injuries accounting for $30 \%$. In Ireland, falls (15\%) and sports (15\%) were the leading causes, while injury at work contributed $5.4 \%$. This may be due to developed nature of the country with less industrial manual workers. Pietrobon observed that assaults were the leading cause of hand injuries in South Africa (9). He attributed this to the period 1992 to 1994 when the country was in transition characterised by violence, social upheaval and uncertainty about the future. In The Netherlands and Denmark however, home and leisure accidents caused by objects and falls were the leading cause of injury to the hand (6).

The predominance of work-related injuries suggests that preventive measures focused at the work place may lead to reduction in the prevalence of occupation-related hand injuries.

Site of injury. The digits were the most affected site compared to the carpus. This finding compares well with the study in Ireland in terms of ratios although the Irish had significantly less injuries on the carpus. Among the digits, the ring and the index fingers were the most injured closely followed by the long finger. This differs from Shaheen's study in which the long finger was the most affected with index finger and thumb next in predominance. The distal phalanges of the index and long fingers were the most affected sites and this is explainable by the fact that these are the leading parts of the body especially in those with occupational injuries.

Pattern of injury: Most of the injuries were open. This pattern may reflect the severity of the force and the nature of the cause at the time of injury. Machine related and assaults involving sharp objects are likely to cause lacerations/ penetrating injuries. The phalanges $(72.9 \%)$ were the most fractured bones followed by the melacarpals (25\%). This is in keeping with site of injury distribution and reflects the fact that the phalanges are the leading part of the hand. 
Of the metacarpals injured, second and fifth were most affected. These metacarpals are on the open side of the hand, therefore exposed to violence of assaults and machine injuries. These figures compare well with those in The Netherlands (10). Here phalangeal fracture prevalence was 59\% while that of metacarpals was 33\%. Hove et al (11) in Belgium observed that the phalanges, metacarpals, and carpal bones accounted for, $46 \%, 36 \%$ and $18 \%$ of the fractures, respectively. Fractures of the scaphoid made up $10.6 \%$ of the total. In Finland a pattern in which lacerations constituted $45 \%$ of the injuries, while fractures represented $26 \%$ was reported (12).

Nerve injuries: In this study the prevalence of nerve injuries was about $2 \%$. This is comparable with the findings of Nieminen et al in Finland who reported a prevalence of $2 \%$ (12). Nieminen's study had a similar prevalence of nerve and tendon injuries. In this study however, the tendon injury prevalence was $17 \%$. It would be expected that the tendon and nerve injury prevalence should be the same as both are usually caused by lacerations. Probably the nerve and tendon injuries were discordant because many of the tendon injuries were in zone 1 and 2 of the hand where tendons and nerve are not as closely related as compared to zone 3 and 4 .

Joint: There was a $10 \%$ rate of joint dislocation with the interphalangeal joints being the most affected. This pattern of injury is in keeping with the distribution of sites injured and the corresponding bone fractures.

In conclussion, hand injuries are a common problem at the accident and emergency units worldwide. This study illustrates the difference in demographicfeatures and pattern of injuries seen at KNH compared to other institutions found in areas with different levels of development. It is further noted that most hand injuries are largely due to preventable causes (occupational/ assaults) and are therefore avoidable. We recommend enhancement of work-place safety measures that would reduce incidence of hand injuries.

\section{ACKNOWLEDGEMENTS}

To the Director KNH for allowing the publication of this article and Dr. Saidi Hassan for assistance during formulation of the study and perusal of the final manuscript.

\section{REFERENCES}

1. Louis, S., Warwick, D., Selvadurai, N., (Eds). The hand, in Apley's syslem of Orthopaedics and Fractures. 8th edition. Oxford University press; (2001), PP 333.

2. Skov, O. The incidence of hospital-treated occupational hand injuries. J. Hand. Surg. 1994; 19: 118-119.

3. Wanjohi, A. A retrospective study on pattern and outcome of metacarpal and phalangeal fractures of the hand as seen in Kenyatta National Hospital. MMed. (Surgery). Dissertation 2000. University of Nairobi.

4. Hill, C., Riaz M., Mozzam, A., et al. A regional audit of hand and wrist injuries: A study of 4873 injuries. J. Hand. 1998; 23:196-200.

5. Shaheen, T., Khalid, K.N. and Basti, H. Epidemiology of hand injury in Qatar. The Middle East J. Emerg. Medicine. 2003; $3: 1-5$.

6. Larsen, C.F., Mulder, S., Johansen, A.M. et al. The epidemiology of hand injuries in The Netherlands and Denmark. Eur. J. Epidemiol. 2004; 19: 323-327.

7. Trybus, M., Lorkowski J., Brongel I,. et al. Causes and consequences of hand injuries. Am. J. Hand Surg. 2006; 192:52-57.

8. Angermann, P. and Lohmann, M. Injuries to the hand and wrist. A study of 50272 injuries. J. Hand Surg. 1993; 18: 642-644.

9. Pietrobon, C. Hand therapy trends in a changing South Africa. J. Hand Ther. 1996; 9: 299-302.

10. Onsellen, E.B.H., Kerin, R.B. and Hage, J.J. Prevalence and distribution of hand fractures. J. Hand Surg. 2003; 28:491-495.

11. Hove, L.M. Fractures of the hand: Distribution and relative incidence. Scand. J. Plast Reconstr. Surg. Hand Surg. 1993; 27:317-319.

12. Nieminen, S., Nurmi, M. and Isberg, U. Hand injuries in Finland. Scand. J. Plast Reconstr. Surg. 1981; 1:57-60. 